\title{
Effects of etanercept and infliximab on bone metabolism indexes in patients with ankylosing spondylitis
}

\author{
CHENGHAI WANG ${ }^{1 *}$ and WEIFENG $\mathrm{LI}^{2 *}$ \\ ${ }^{1}$ Department of Orthopaedic Surgery, The Affiliated Hospital of Hebei University of Engineering, Handan, Hebei 056000; \\ ${ }^{2}$ Department of Orthopaedic Surgery, The First Central Hospital of Baoding, Baoding, Hebei 071000, P.R. China
}

Received September 13, 2019; Accepted November 12, 2019

DOI: $10.3892 /$ etm.2019.8266

\begin{abstract}
Effect of etanercept and infliximab on bone metabolism indexes in patients with ankylosing spondylitis (AS) were evaluated. The clinical data of 80 patients with ankylosing spondylitis admitted to Affiliated Hospital of Hebei University of Engineering from June 2015 to March 2016 were selected. There were 39 patients treated with Enbrel as Enbrel group and 41 patients treated with Infliximab as Infliximab group. The general data of the two groups of patients were collected and various indexes before and 12 and 24 weeks after treatment were recorded. Adverse reactions of the two groups of patients after treatment were recorded and the clinical efficacy of the drugs was evaluated. C-reactive protein (CRP) and erythrocyte sedimentation rate (ESR) levels in both groups decreased significantly before and 12 and 24 weeks after treatment $(\mathrm{P}<0.05)$, and 24 weeks after treatment showed a downward trend compared with 12 weeks $(\mathrm{P}<0.05)$. The $\beta$-collagen special sequence $(\beta-\mathrm{CTX})$ level in the two groups was significantly lower after treatment than before $(\mathrm{P}<0.0001)$. The adverse reaction rate of Infliximab group $(21.95 \%)$ was higher than that of Enbrel group $(5.13 \%)(\mathrm{P}>0.05)$. The morning stiffness time, BASDAI and BASFI indexes of the two groups of patients after treatment were significantly lower than those before treatment $(\mathrm{P}<0.0001)$. Schober test was significantly higher than that before treatment $(\mathrm{P}<0.0001)$; BASDAI in Infliximab group was lower than that in etanercept group $(\mathrm{P}<0.05)$. Both etanercept and infliximab have good therapeutic effects on AS, which can reduce the bone metabolism level of $\beta$-CTX in AS patients and effectively improve the symptoms of affected medullary joints. The short-term
\end{abstract}

Correspondence to: Dr Weifeng Li, Department of Orthopaedic Surgery, The First Central Hospital of Baoding, 320 Chengchang Street, Baoding, Hebei 071000, P.R. China

E-mail: v6t4qy@163.com

*Contributed equally

Key words: etanercept, infliximab, ankylosing spondylitis, bone metabolism index efficacy of the two groups of patients is similar, but the incidence of adverse reactions of etanercept is slightly lower than that of infliximab.

\section{Introduction}

Ankylosing spondylitis (AS) is a chronic autoimmune disease (1). The morbidity of AS in China is $\sim 0.3 \%$, and the onset age is at 13-31 years, with a peak at 20-30 years (2). AS mainly occurs in spinal column, skeleton, peripheral joints and extra-articular tissues, mainly manifested as backache, and accompanied by peripheral arthritis, attachment point inflammation, and proctitis $(3,4)$. In the early stage of onset, $50-92 \%$ patients are accompanied by osteopenia or osteoporosis (5-7), and often accompanied by fractures and neurological complications, which seriously affect the treatment and prognosis of AS patients. Smith (8) considered that the pathogenesis of AS is related to genetic, infection, immunity and physical and chemical factors. At present, there is no cure for AS, but timely treatment can relieve patients' pain and improve their quality of life (9).

The drugs commonly used in clinic are infliximab and etanercept, which are tumor necrosis factor- $\alpha$ (TNF- $\alpha$ ) antagonists. TNF- $\alpha$ is an important inflammatory cytokine in the pathogenesis of AS (10). TNF- $\alpha$ antagonist has significant effect in treating AS patients $(11,12)$, and in $30 \%$ of patients symptoms are relieved by $70-80 \%$ in short-term treatment (13). Advanced AS patients will be accompanied by severe joint dysfunction, so early diagnosis is very important for AS patients. In the early stage of AS, C-reactive protein (CRP) and erythrocyte sedimentation rate (ESR) increase rapidly, so ESR and CRP are important evaluation indexes for clinical auxiliary diagnosis $(14,15)$. Recent studies have found that biochemical changes of bone metabolism precede systemic osteoporosis and joint stiffness $(16,17)$, which can also provide basis for early diagnosis of AS (18).

In this study, various indexes were detected before and after treatment, bone metabolism indexes, such as bone-specific alkaline phosphatase (BALP), $\beta$-collagen special sequence $(\beta$-CTX), $C$-reactive protein $(\mathrm{CRP})$ and erythrocyte sedimentation rate (ESR), and adverse reactions and the clinical efficacy of the drugs were evaluated to explore the effect of etanercept and infliximab on AS patients and the effect on bone metabolism index. 


\section{Patients and methods}

General information. Clinical data of 80 patients with AS admitted to Affiliated Hospital of Hebei University of Engineering (Handan, China) from June 2015 to March 2016 were selected into the study. The average age of the 39 AS patients treated with etanercept was $29.68 \pm 7.24$ years, with 21 males and 18 females. Further 41 AS patients treated with infliximab were the control group with an average age of $30.48 \pm 7.18$ years, with 22 males and 19 females.

Inclusion criteria were as follows: The treatment conformed to New York AS Diagnostic Criteria (19) revised in 1984; patients aged 20-50 years; the duration of illness did not exceed 3 years; patients accompanied by family members on admission; patients with complete clinical data and good compliance.

Exclusion criteria were as follows: patients unable to cooperate with the examination due to other factors such as aphasia and dysphoria; patients who had received etanercept and infliximab therapy in the prior 6 months; HIV antibody positive patients; patients participated in other clinical trials; patients with severe organic diseases; patients had previous history of mental illness and family history of mental illness; patients had a history of drug dependence.

This study was approved by the Ethics Committee of Affiliated Hospital of Hebei University of Engineering. All the patients and their families were informed in advance and signed a complete informed consent form.

\section{Method}

Treatment methods. Thirty-nine patients in the etanercept group received intermittent administration for 24 weeks (etanercept; Shenzhen Phys Biotechnology Co., Ltd., item no. 152). Subcutaneous injection was carried out twice a week for the first eight weeks $(20 \mathrm{mg})$, once a week for the ninth to sixteenth weeks $(15 \mathrm{mg})$, and once every two weeks for the last eight weeks $(10 \mathrm{mg})$. Further 41 patients in infliximab group received intermittent administration for 24 weeks (infliximab; Shanghai Teramabs Biotechnology Co., Ltd. item no. TM-Infl-00002_1), $100 \mathrm{mg}$ in the first week, the second week and the sixth week, and the same dose every six weeks. Patient's rest and diet were adjusted, appropriate rehabilitation exercise and adequate sleep were maintained.

Blood collection. A total of $4 \mathrm{ml}$ of fasting peripheral blood was collected early in the morning before treatment, 12 weeks after treatment and at 24 weeks. Sample was put into anticoagulant tubes, and sent to clinical laboratory to examine CRP and ESR of the patients. After coagulation for $60 \mathrm{~min}\left(20-25^{\circ} \mathrm{C}\right)$, the blood sample was centrifuged at $1,006.2 \mathrm{x}$ for $10 \mathrm{~min}$ with a centrifuge radius of $10 \mathrm{~cm}$ and a centrifuge temperature of $4^{\circ} \mathrm{C}$, the upper serum was separated and stored for later use to avoid hemolysis and repeated freezing and thawing. After obtaining the upper serum, the serum bone-specific alkaline phosphatase (BALP) (BALP ELISA kit; Wuhan Aimosaisi Technology Co., Ltd.; item no. ELA-E1091r), $\beta$ - $\beta$-crosslaps $(\beta$-CTX) ( $\beta$-CTX ELISA kit; Shanghai Zhenyu Biotechnology Co., Ltd.; item no. E-EL-H0960km-1) and the level of bone metabolism index was detected by enzyme-linked immunosorbent assay. The detection process was strictly carried out in accordance with the instruction manual of the kit. The specific steps of ELISA were as follows: $100 \mu \mathrm{l}$ of sample and standard substance were added into reagent diluent, the plate was sealed, incubated at room temperature for $2 \mathrm{~h}$, and washed; and $100 \mu \mathrm{l}$ of detection antibody was added to each well, the plate was sealed, incubated at room temperature for $2 \mathrm{~h}$, and washed; then $100 \mu 1$ of streptavidin-HRP working diluent was added to each well. The plate was sealed, incubated at room temperature in the dark for $20 \mathrm{~min}$, and washed. Then $100 \mu \mathrm{l}$ of substrate solution was added to each well, incubated at $37^{\circ} \mathrm{C}$ in the dark for $20 \mathrm{~min}, 50 \mu \mathrm{l}$ of termination solution was added and ELXS00 microplate reader was used at $450 \mathrm{~nm}$ within $15 \mathrm{~min}$.

Observation indicators. The changes of CRP and ESR levels before and 12 and 24 weeks after treatment were observed to evaluate the effect of etanercept and infliximab on laboratory indexes of AS patients. The bone metabolism level (BALP, $\beta$-CTX), morning stiffness time, Schober test time, AS activity index (BASDAI) (20), AS function index (BASFI) (21) and the clinical efficacy and adverse reactions of the two groups of patients before and after treatment were recorded.

\section{Evaluation indicators}

Efficacy evaluation. Efficacy evaluation (19): Cure: no morning stiffness, limited activity, pain in trunk joints, ESR and CRP returned to normal. Markedly effective: morning stiffness, movement restriction, trunk joint pain, ESR and CRP decreased significantly. Effective: morning stiffness, movement restriction, trunk joint pain, ESR and CRP decreased. Ineffective: morning stiffness, movement restriction, trunk joint pain, ESR and CRP did not decrease.

SPSS 20.0 (IBM Corp.) was used for all statistical analysis of the experimental results. GraphPad Prism 7 (GraphPad Software Co., Ltd.) was used for visualizing the results. Enumeration data was expressed as [n(\%)], and Chi-square test was used for comparison among groups. The measurement data were expressed as (mean $\pm \mathrm{SD}$ ), the two groups were compared by paired t-test, the comparison of multiple time-points was analyzed by repeated measurement variance, and LSD-t was used in back testing. $\mathrm{P}<0.05$ was regarded as statistically significant.

\section{Results}

Comparison of general data between the two groups. There was no difference in general clinical data between the two groups in terms of age, sex, body mass index, smoking and drinking history, education level and complications $(\mathrm{P}>0.05)$ (Table I).

CRP and ESR levels before and after treatment in the two groups of patients. The CRP and ESR levels between the two groups before and after treatment were compared (Figs. 1 and 2). There wasno significant difference inCRP levels between the two groups before treatment $(37.58 \pm 19.89$ and $38.62 \pm 20.41 \mathrm{mg} / \mathrm{l}), 12$ weeks after treatment $(9.65 \pm 3.94$ and $8.94 \pm 3.81 \mathrm{mg} / \mathrm{l})$ or 24 weeks after treatment $(6.78 \pm 2.72$ and $6.21 \pm 2.25 \mathrm{mg} / \mathrm{l})(\mathrm{P}>0.05)$. CRP levels in both groups decreased significantly before treatment, 12 and 24 weeks after treatment $(\mathrm{P}<0.05)$, and there was a downward trend from 12 to 24 weeks after treatment $(\mathrm{P}<0.05)$. There was no significant difference in ESR level between the two groups before treatment $(53.67 \pm 18.75$ and $55.71 \pm 19.87 \mathrm{~mm} / \mathrm{h}), 12$ weeks after treatment $(16.43 \pm 6.74$ and $17.68 \pm 7.12 \mathrm{~mm} / \mathrm{h})$ or 24 weeks after treatment $(9.74 \pm 2.65$ and $10.81 \pm 3.10 \mathrm{~mm} / \mathrm{h})(\mathrm{P}>0.05)$. CRP levels in both groups decreased significantly before treatment, 
Table I. Comparison of clinical general data (mean \pm SD), n[\%].

\begin{tabular}{|c|c|c|c|c|}
\hline & $\begin{array}{l}\text { Enbrel group } \\
\qquad(\mathrm{n}=39)\end{array}$ & $\begin{array}{l}\text { Infliximab group } \\
\qquad(\mathrm{n}=41)\end{array}$ & $\chi^{2 / t}$ value & P-value \\
\hline Average age (years) & $29.68 \pm 7.24$ & $30.48 \pm 7.18$ & 0.50 & 0.62 \\
\hline Sex & & & 0.00 & 0.99 \\
\hline Male & $21(53.85)$ & $22(53.66)$ & & \\
\hline Female & $18(46.15)$ & $19(46.34)$ & & \\
\hline Body mass index $\left(\mathrm{kg} / \mathrm{m}^{2}\right)$ & $21.51 \pm 3.42$ & $20.89 \pm 3.58$ & 0.79 & 0.43 \\
\hline Smoking & & & 0.01 & 0.92 \\
\hline Yes & $11(28.21)$ & $12(29.27)$ & & \\
\hline No & $28(71.79)$ & $29(70.73)$ & & \\
\hline Drinking & & & 0.28 & 0.59 \\
\hline Yes & $5(12.82)$ & $7(17.07)$ & & \\
\hline No & $34(87.18)$ & $34(82.93)$ & & \\
\hline Educational level & & & 0.03 & 0.86 \\
\hline Junior high school & $7(17.95)$ & $8(19.51)$ & & \\
\hline College degree or above & $32(82.05)$ & $33(80.49)$ & & \\
\hline \multicolumn{5}{|l|}{ Complication } \\
\hline Hypertension & $6(15.38)$ & $8(19.51)$ & 0.24 & 0.63 \\
\hline High blood lipid & $4(10.26)$ & $3(7.32)$ & 0.22 & 0.64 \\
\hline
\end{tabular}

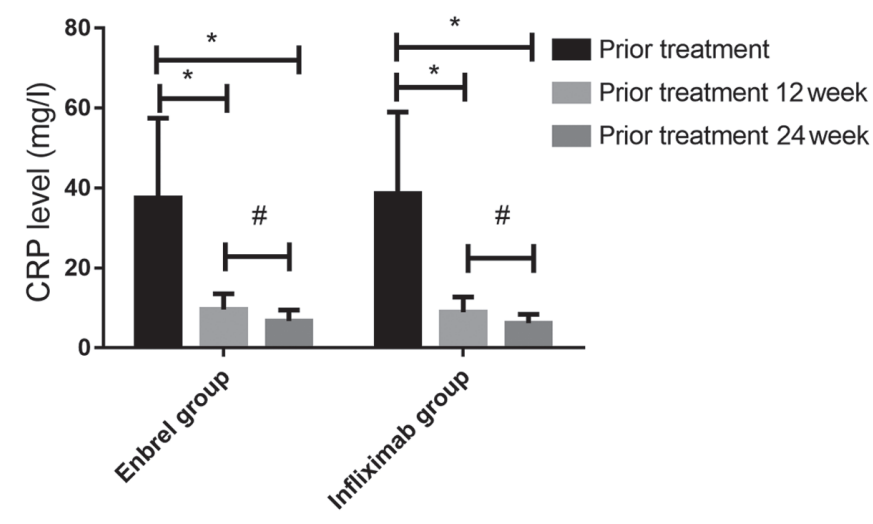

Figure 1. Comparison of CRP levels of two groups of patients before and after treatment. There was no significant difference in CRP levels between the two groups before and 12 and 24 weeks after treatment $(P>0.05)$. CRP levels in both groups decreased significantly before treatment, 12 and 24 weeks after treatment $(\mathrm{P}<0.05)$, and there was a downward trend from 12 to 24 weeks after treatment $(\mathrm{P}<0.05) .{ }^{*} \mathrm{P}<0.05$ compared with that before treatment in the same group; ${ }^{\#} \mathrm{P}<0.05$ compared with 12 and 24 weeks after treatment in the same group. CRP, C-reactive protein.

12 and 24 weeks after treatment $(\mathrm{P}<0.05)$, and there was a downward trend from 12 to 24 weeks after treatment $(\mathrm{P}<0.05)$.

Comparison of bone metabolism levels before and after treatment between the two groups. The bone metabolism levels between the two groups before and after treatment were compared (Figs. 3 and 4). There was no significant difference in BALP level between Enbrel group and Infliximab group before treatment $(18.72 \pm 8.62$ and $18.98 \pm 8.51 \mu \mathrm{g} / \mathrm{l})$ and after treatment $(17.59 \pm 7.71$ and $17.84 \pm 7.64 \mu \mathrm{g} / 1)(\mathrm{P}>0.05)$, and there was no significant difference between the two groups

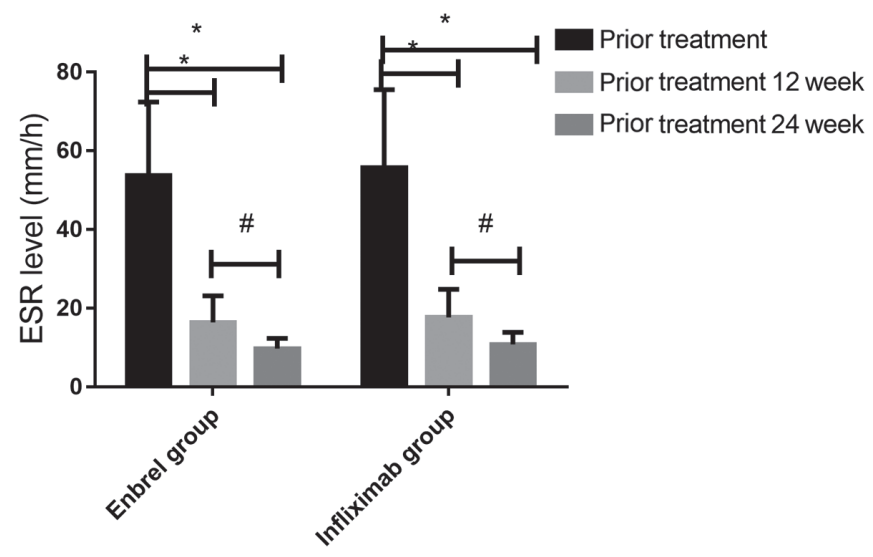

Figure 2. Comparison of ESR levels of two groups of patients before and after treatment. There was no significant difference in ESR level between the two groups before and 12 and 24 weeks after treatment $(\mathrm{P}>0.05)$. CRP levels in both groups decreased significantly before treatment, 12 and 24 weeks after treatment $(\mathrm{P}<0.05)$, and there was a downward trend from 12 to 24 weeks after treatment $(\mathrm{P}<0.05)$. $\mathrm{P}<0.05$ compared with that before treatment in the same group; ${ }^{~} \mathrm{P}<0.05$ compared with 12 and 24 weeks after treatment in the same group. ESR, erythrocyte sedimentation rate; CRP, C-reactive protein.

before and after treatment $(\mathrm{P}>0.05)$. After treatment, $\beta$-CTX levels in Enbrel group and Infliximab group $(362.58 \pm 211.45$ and $354.74 \pm 231.52 \mathrm{ng} / \mathrm{ml})$ were significantly lower than those before treatment $(638.52 \pm 268.74$ and $642.75 \pm 271.66 \mathrm{ng} / \mathrm{ml})$ $(\mathrm{P}<0.0001)$, but there was no significant difference between the two groups before and after treatment $(\mathrm{P}>0.05)$.

Curative effect of the two groups before and after treatment. Statistical analysis of the clinical efficacy of the two groups of patients after treatment (Table II) showed that the total 
Table II. Comparison of clinical efficacy n[\%].

\begin{tabular}{|c|c|c|c|c|c|}
\hline & Cure & Markedly effect & Effective & Ineffective & Total efficiency \\
\hline Enbrel group $(n=39)$ & $11(28.20)$ & $12(30.77)$ & $12(30.77)$ & $4(10.26)$ & 35 (89.74) \\
\hline Infliximab group $(n=41)$ & $12(29.27)$ & $13(31.70)$ & $12(29.27)$ & $4(9.76)$ & $37(90.24)$ \\
\hline$\chi^{2}$ value & - & - & - & - & 0.01 \\
\hline P-value & - & - & - & - & 0.94 \\
\hline
\end{tabular}

Table III. Comparison of postoperative adverse reactions $\mathrm{n}[\%]$.

\begin{tabular}{|c|c|c|c|c|c|c|c|}
\hline & $\begin{array}{l}\text { Skin } \\
\text { allergy }\end{array}$ & $\begin{array}{c}\text { Hot } \\
\text { flashes }\end{array}$ & Infection & $\begin{array}{l}\text { Respiratory } \\
\text { tract reaction }\end{array}$ & $\begin{array}{l}\text { Gastrointestinal } \\
\text { tract reaction }\end{array}$ & $\begin{array}{l}\text { Skin reaction at } \\
\text { injection site }\end{array}$ & $\begin{array}{c}\text { Incidence of } \\
\text { adverse reactions }\end{array}$ \\
\hline Enbrel group $(n=39)$ & $0(0.00)$ & $0(0.00)$ & $0(0.00)$ & $0(0.00)$ & $1(2.56)$ & $1(2.56)$ & $2(5.13)$ \\
\hline Infliximab group $(n=41)$ & $2(4.88)$ & $0(0.00)$ & $2(4.88)$ & $2(4.88)$ & $3(7.32)$ & $0(0.00)$ & $9(21.95)$ \\
\hline$\chi^{2}$ value & - & - & - & - & - & - & 4.77 \\
\hline P-value & - & - & - & - & - & - & 0.03 \\
\hline
\end{tabular}

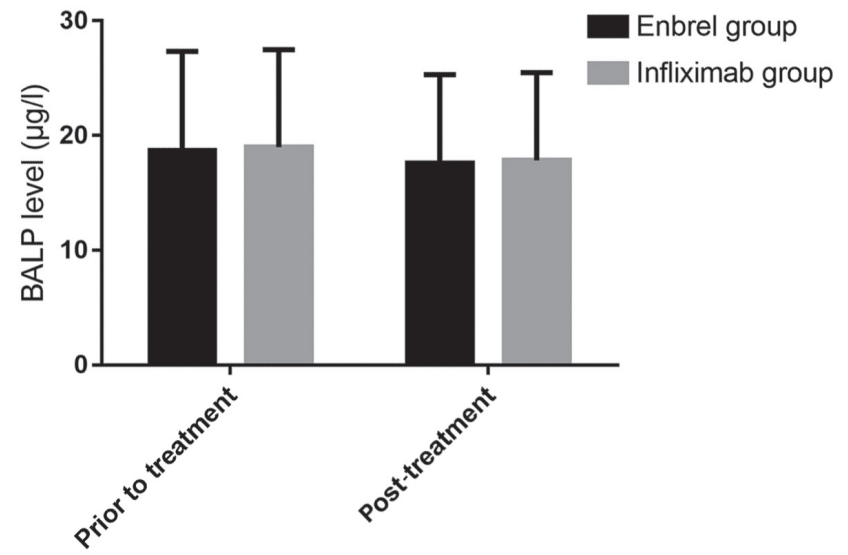

Figure 3. Comparison of bone metabolism level-BALP between two groups before and after treatment. BALP level of patients in Enbrel group and Infliximab group had no significant difference before and after treatment, and there was no significant difference in the same group before and after treatment. BALP, bone-specific alkaline phosphatase.

effective rate of Enbrel group (89.74\%) and Infliximab group $(90.24 \%)$ had no significant difference $(\mathrm{P}>0.05)$.

Comparison of adverse reactions between the two groups of patients. The adverse reactions of the two groups of patients after treatment were compared (Table III). The adverse reactions of the two groups of patients were relieved after symptomatic treatment. The adverse reaction rate of Infliximab group $(21.95 \%)$ was higher than that of Enbrel group (5.13\%) ( $\mathrm{P}>0.05)$.

Comparison of various indexes between the two groups before and after treatment. The various indexes between the two groups before and after treatment were compared (Table IV). The morning stiffness time, BASDAI, BASFI and Schober tests of the two groups were basically the same before treatment, and there was no difference between the two groups ( $\mathrm{P}>0.05)$. After treatment, the morning stiffness time, BASDAI

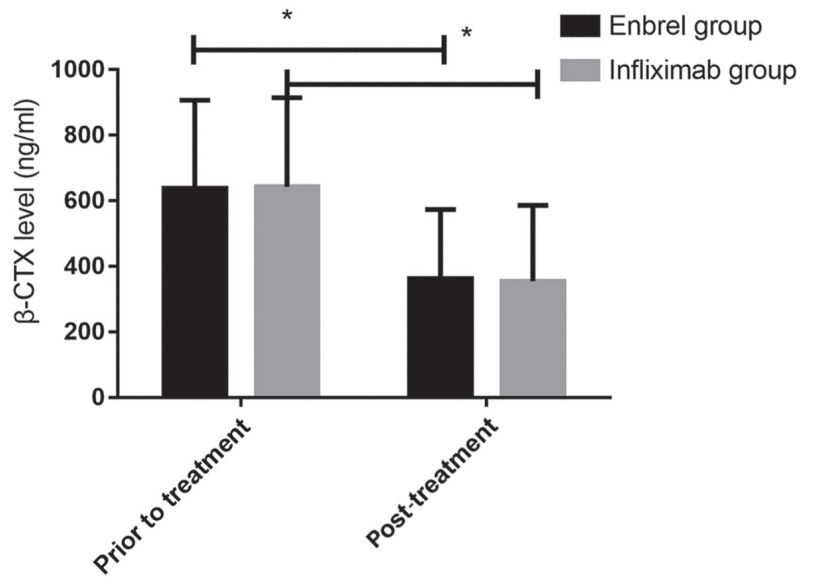

Figure 4. Comparison of bone metabolism level of $\beta$-CTX between two groups before and after treatment. The $\beta$-CTX level in Enbrel group and Infliximab group decreased significantly after treatment, but there was no significant difference between the two groups before and after treatment. ${ }^{*} \mathrm{P}<0.05$ compared with the same group before and after treatment. $\beta$-CTX, $\beta$-collagen special sequence.

and BASFI indexes of the two groups were significantly lower than before treatment $(\mathrm{P}<0.0001)$. Schober test significantly increased $(\mathrm{P}<0.0001)$. BASDAI in Infliximab group was lower than that in etanercept group $(\mathrm{P}<0.05)$.

\section{Discussion}

The monoclonal antibody infliximab formed by chimeric mouse and human, is a combined soluble TNF- $\alpha$ and transmembrane TNF- $\alpha$ receptor, thus blocking the pathological effect and signal conduction by TNF- $\alpha(22,23)$. Etanercept with receptor-immunoglobulin fusion technology is composed of the extracellular ligand binding site of human tumor necrosis factor receptor 2 (TNF-2/p75) and Fc fragment of human IgG1. The fusion protein is expressed in vitro. Soluble TNF- $\alpha$ in plasma and on the surface of cell membrane is highly compatible with 
Table IV. Comparison of various indexes of two groups of patients before and after treatment (mean \pm SD).

Stiffness in the

morning ( $\min )$
Schober

test
BASDAI

BASFI

\begin{tabular}{lcccc}
\hline Enbrel group $(\mathrm{n}=39)$ & & & & \\
Before treatment & $74.14 \pm 21.65$ & $2.21 \pm 1.12$ & $3.91 \pm 1.56$ & $32.58 \pm 10.56$ \\
After treatment & $35.45 \pm 16.21$ & $5.05 \pm 1.54$ & $1.65 \pm 0.48^{\mathrm{a}}$ & $9.68 \pm 3.04$ \\
t value & 8.93 & 9.31 & $<.65$ & 13.01 \\
P-value & $<0.0001$ & $<0.0001$ & $<0.0001$ & $<0.0001$ \\
Infliximab group $(\mathrm{n}=41)$ & & & $3.87 \pm 1.34$ & $33.98 \pm 11.47$ \\
Before treatment & $72.56 \pm 20.48$ & $2.35 \pm 1.34$ & $1.04 \pm 0.51^{\mathrm{a}}$ & $8.77 \pm 3.12$ \\
After treatment & $34.28 \pm 15.67$ & $5.62 \pm 1.47$ & 12.64 & 13.58 \\
t value & 9.51 & 10.53 & $<0.0001$ & $<0.0001$ \\
P-value & $<0.0001$ & $<0.0001$ & & \\
\hline
\end{tabular}

${ }^{a} \mathrm{P}<0.05$ compared with the same items between the two groups after treatment.

this fusion protein, which is neutralized by etanercept, resulting in loss of biological activity of TNF- $\alpha$ and achieving inhibition of abnormal immune response and inflammatory process mediated by receptor (24), thus effectively treating AS.

Bone metabolism markers are divided into bone formation markers, bone turnover markers, bone absorption markers and osteoporosis-related hormone markers. $\beta$-CTX is an index of bone resorption, and some researches have shown that it is a valuable and reliable index for evaluating bone resorption $(25,26)$. However, in this study, there was no significant difference in the level of BALP before and after treatment between Enbrel group and Infliximab group $(\mathrm{P}>0.05)$, and there was no significant difference in the same group before and after treatment. Consistent with the results of a previous study (27), it was presumed that bone metabolism index BALP has little effect on AS. In this study, the morning stiffness time, BASDAI and BASFI indexes of the two groups of patients after treatment were significantly lower than before treatment $(\mathrm{P}<0.0001)$, and Schober test was significantly higher $(\mathrm{P}<0.0001)$. Consistent with the reduction of morning stiffness time in the clinical efficacy of etanercept in the treatment of AS by Liu et al (28).

According to the observation of the therapeutic effect of infliximab on AS (29), the indexes of BASDAI and BASFI were significantly lower than those before treatment $(\mathrm{P}<0.0001)$, which indicates that etanercept and infliximab can effectively cure AS patients. However, it is also found that the BASDAI score of infliximab group is lower than that of Enbrel group $(\mathrm{P}<0.05)$, and infliximab can reduce pain more than etanercept. However, the total effective rate of Enbrel group (89.74\%) and Infliximab group (90.24\%) had no significant difference $(\mathrm{P}>0.05)$, which is consistent with the clinical efficacy of McLeod et al (30) in the treatment of juvenile AS with etanercept and infliximab. It was also concluded that CRP and ESR levels in Enbrel group and Infliximab group decreased significantly $(\mathrm{P}<0.05)$ before and at 12 and 24 weeks after treatment, and showed a downward trend $(\mathrm{P}<0.05)$ at 24 weeks after treatment compared with 12 weeks after treatment, indicating that infliximab and etanercept can control the laboratory indexes well and have a good therapeutic effect on AS patients. However, the adverse reaction rate of Infliximab group (21.95\%) was higher than that of Enbrel group (5.13\%), which is consistent with previous results (30). Further research is needed because there are scarce data, and in our study the results caused by occult diseases cannot be excluded. In this study, the $\beta$-CTX level of Enbrel group and Infliximab group decreased significantly after treatment compared with that before treatment $(\mathrm{P}<0.0001)$. Korczowska et al (31) also found potential clinical value in detecting bone metabolism indexes in AS patients and the differences of bone metabolism indexes expressed by AS patients, especially $\beta$-CTX with obvious change in characteristics in AS patients, CRP and ESR were combined for detection. It can provide a certain basis for early diagnosis and differentiation of AS. The study also concluded that there was no significant difference in $\beta$-CTX levels between the two groups before and after treatment $(\mathrm{P}>0.05)$, further demonstrating that the clinical efficacy of infliximab and etanercept are basically the same.

The present study evaluated the effect of etanercept and infliximab on bone metabolism indexes of AS patients by detecting bone metabolism index (BALP, $\beta$-CTX) levels, CRP and ESR before and after treatment, recording adverse reactions of the two groups of patients after treatment and evaluating the clinical efficacy of the two groups of drugs.

Collectively, etanercept and infliximab improved the therapeutic effect on AS patients. All indexes are decreased, effectively reducing bone metabolism indexes, which is worthy of clinical promotion.

\section{Acknowledgements}

Not applicable.

\section{Funding}

No funding was received.

\section{Availability of data and materials}

The datasets used and/or analyzed during the current study are available from the corresponding author on reasonable request. 


\section{Authors' contributions}

CW wrote the manuscript. CW and WL conceived and designed the study. CW was responsible for the collection and analysis of the experimental data. WL interpreted the data and drafted the manuscript. CW and WL revised the manuscript critically for important intellectual content. Both authors read and approved the final manuscript.

\section{Ethics approval and consent to participate}

The study was approved by the Ethics Committee of Affiliated Hospital of Hebei University of Engineering (Handan, China). Patients who participated in this research had complete clinical data. Signed informed consents were obtained from the patients and/or guardians.

\section{Patient consent for publication}

Not applicable.

\section{Competing interests}

The authors declare that they have no competing interests.

\section{References}

1. Braun J and Sieper J: Ankylosing spondylitis. Lancet 369: 1379-1390, 2007.

2. Biasi D, Carletto A, Caramaschi P, Pacor ML, Maleknia T and Bambara LM: Efficacy of methotrexate in the treatment of ankylosing spondylitis: a three-year open study. Clin Rheumatol 19: 114-117, 2000.

3. Quaden DH, De Winter LM and Somers V: Detection of novel diagnostic antibodies in ankylosing spondylitis: An overview. Autoimmun Rev 15: 820-832, 2016.

4. Stolwijk C, Essers I, van Tubergen A, Boonen A, Bazelier MT, De Bruin ML and de Vries F: The epidemiology of extra-articular manifestations in ankylosing spondylitis: A population-based matched cohort study. Ann Rheum Dis 74: 1373-1378, 2015.

5. Davey-Ranasinghe N and Deodhar A: Osteoporosis and vertebral fracture in ankylosing spondylitis. Curr Opin Rheumatol 25: 509-516, 2013.

6. van der Weijden MA, Claushuis TA, Nazari T, Lems WF, Dijkmans BA and van der Horst-Bruinsma IE: High prevalence of low bone mineral density in patients within 10 years of onset of ankylosing spondylitis: A systematic review. Clin Rheumatol 31: 1529-1535, 2012.

7. Singh HJ, Nimarpreet K, Ashima, Das S, Kumar A and Prakash S: Study of bone mineral density in patients with ankylosing spondylitis. J Clin Diagn Res 7: 2832-2835, 2013.

8. Smith JA: Update on ankylosing spondylitis: Current concepts in pathogenesis. Curr Allergy Asthma Rep 15: 489, 2015.

9. Machado MA, Moura CS, Ferré F, Bernatsky S, Rahme E and Acurcio Fde A: Treatment persistence in patients with rheumatoid arthritis and ankylosing spondylitis. Rev Saude Publica 50: 50, 2016.

10. Davis JC: Understanding the role of tumor necrosis factor inhibiton in ankylosing spondylitis. Semin Arthritis Rheum 34: 268-278, 2005

11. Prince DS, McUuigan LE and McGirr EE: Working life and physical activity in ankylosing spondylit is pre and post antitumor necrosis factor-alpha therapy. Int J Rheum Dis 17: 165-172, 2014.

12. Maxwell LJ, Zochling J, Boonen A, Singh JA, Veras MM, Tanjong Ghogomu E, Benkhalti Jandu M, Tugwell P and Wells GA: TNF-alpha inhibitors for ankylosing spondylitis. Cochrane Database Syst Rev: Apr 18, 2015 (Epub ahead of print). doi: 10.1002/14651858.CD005468.pub2

13. Poddubnyy DA, Song IH and Sieper J: The safety of celecoxib in ankylosing spondylitis treatment. Expert Opin Drug Saf 7: 401-409, 2008
14. Rauner M, Thiele S, Fert I, Araujo LM, Layh-Schmitt G, Colbert RA, Hofbauer C, Bernhardt R, Bürki A, Schwiedrzik J, et al: Loss of bone strength in HLA-B27 transgenic rats is characterized by a high bone turnover and is mainly osteoclast-driven. Bone 75: 183-191, 2015.

15. Rostom S, Dougados M and Gossec L: New tools for diagnosing spondyloarthropathy. Joint Bone Spine 77: 108-114, 2010.

16. Gerdhem P, Ivaska KK, Alatalo SL, Halleen JM, Hellman J, Isaksson A, Pettersson K, Väänänen HK, Akesson K and Obrant KJ: Biochemical markers of bone metabolism and prediction of fracture in elderly women. J Bone Miner Res 19: 386-393, 2004.

17. Garnero P and Delmas PD: Contribution of bone mineral density and bone turnover markers to the estimation of risk of osteoporotic fracture in postmenopausal women. J Musculoskelet Neuronal Interact 4: 50-63, 2004.

18. Garnero P, Ferreras M, Karsdal MA, Nicamhlaoibh R, Risteli J, Borel O, Qvist P, Delmas PD, Foged NT and Delaissé JM: The type I collagen fragments ICTP and CTX reveal distinct enzymatlc pathways of bone collagen degradation. J Bone Miner Res 18: 859-867, 2003.

19. van der Linden S, Valkenburg HA and Cats A: Evaluation of diagnostic criteria for ankylosing spondylitis. A proposal for modification of the New York criteria. Arthritis Rheum 27: 361-268, 1984.

20. Song J, Zhou L, Chen L and Wu X: Comparison of ASDAS, RAPID3 and BASDAI in assessing disease activity of patients with ankylosing spondylitis. Acad J Second Mil Med Univ 36: 909-913, 2015.

21. Garrett S, Jenkinson T, Kennedy LG, Whitelock H, Gaisford P and Calin A: A new approach to defining disease status in AS: The Bath Ankylosing Spondylitis Disease Activity Index (BASDAI). J Rheumatol 21: 2286-2291, 1994.

22. Neubauer S, Cifaldi M, Mittendorf T, Ganguli A, Wolff M and Zeidler J: Biologic TNF inhibiting agents for treatment of rheumatoid arthritis persistence and dosing patterns in Germany. Health Econ Rev 4: 32, 2014.

23. Fleischmann RM, Cohen SB, Moreland LW, Schiff M, Mease PJ, Smith DB, Keenan G and Kremer JM; iRAMT Study Group: Methotrexate dosage reduction in patients with rheumatoid arthritis beginning therapy with infliximab: the Infliximab Rheumatoid Arthritis Methotrexate Tapering (iRAMT) trial. Curr Med Res Opin 21:1181-1190, 2005.

24. Zhang J, Zhang YM and Zhang JL: Efficacy of etanercept in patients with ankylosing spondylitis: A double-blind, randomized, placebo controlled trial. Zhongguo Xin Yao Za Zhi 18: 1846-1849, 1881, 2009 (In Chinese).

25. Chu B, Lu MQ, Wu MQ, Shi L, Fu LN, Gao S, Fang LJ, Xiang QQ and Bao L: Clinical characteristics of bone disease in multiple myeloma and clinical significance of monitoring bone metabolic markers. Zhonghua Yi Xue Za Zhi 96: 1424-1429, 2016. (In Chinese).

26. Fang Z, Li Y, Jiang Y and Yang F: Significance of dynamic monitoring of bone metabolites in patients with ankylosing spondylitis. Zhong Guo Yi Yuan Xie Hui 4: 447-449, 2014 (In Chinese).

27. Speden DJ, Calin AI, Ring FJ and Bhalla AK: Bone mineral density, calcaneal ultrasound, and bone turnover markers in women with ankylosing spondylitis. J Rheumatol 29: 516-521, 2002.

28. Liu YF, Dong H, Tu SH, Zheng CH,Liu PL and Hu YH: Etanercept in the treatment of ankylosing spondylitis: A systematic review and meta-analysis. Exp Ther Med 8: 1585-1592, 2014.

29. Marakli SS, Uzun S, Ozbek S and Tuncer I: Dermatitis herpetiformis in a patient receiving infliximab for ankylosing spondylitis. Eur J Dermatol 18: 88-89, 2008.

30. McLeod C, Bagust A, Boland A, Dagenais P, Dickson R, Dundar Y, Hill RA, Jones A, Mujica Mota R and Walley T: Adalimumab, etanercept and infliximab for the treatment of ankylosing spondylitis: a systematic review and economic evaluation. Health Technol Assess 11: 1-158, 2007.

31. Korczowska I, Przepiera-Bedzak H, Brzosko M, Lacki JK, Trefler J and Hrycaj P: Bone tissue metabolism in men with ankylosing spondylitis. Adv Med Sci 56: 264-269, 2011.

This work is licensed under a Creative Commons Attribution-NonCommercial-NoDerivatives 4.0 International (CC BY-NC-ND 4.0) License. 